\title{
Size-structured habitat selection by arapaima in floodplain lakes of the Lower Amazon
}

\author{
Jordan C. Richard ${ }^{1}$ | Leandro Castello ${ }^{1}$ (D) | Daniel J. Gurdak ${ }^{2}$ | Brandon K. Peoples ${ }^{3}$ (D) । \\ Paul L. Angermeier ${ }^{4}$
}

${ }^{1}$ Department of Fish and Wildlife Conservation, Virginia Tech, Blacksburg, Virginia

${ }^{2}$ Department of Environmental and Forest Biology, State University of New York, Syracuse, New York

${ }^{3}$ Department of Forestry and Environmental Conservation, Clemson University, Clemson, South Carolina

${ }^{4}$ U.S. Geological Survey, Virginia Cooperative Fish and Wildlife Research Unit, Department of Fish and Wildlife Conservation, Virginia Tech, Blacksburg, Virginia

Correspondence

Leandro Castello, Department of Fish and Wildlife Conservation, Virginia Tech,

Blacksburg, VA, USA.

Email: leandro@vt.edu

\section{Abstract}

1. Human modification of floodplain ecosystems is widespread and a major threat to fish populations, particularly in the tropics where fish diversity and rates of floodplain degradation are high. Identifying measures to minimize the susceptibility of floodplain fishes to habitat modification requires understanding dry-season lake habitat selection for species of conservation concern.

2. This study examined the effects of environmental factors on dry-season floodplain lake habitat selection by arapaima (Arapaima spp.) and determined the extent to which they differed across three size classes. In floodplain lakes of the lower Amazon River, variables were measured at locations representing habitat availability and compared with measurements taken where arapaima were observed during surface breathing. Regression models were used to account for between-lake variation in the presence of arapaima owing to nearby fishing communities. The probability of arapaima presence at each sample location was modelled based on the variables measured.

3. The results indicated that arapaima expressed distinct habitat selection patterns, which differed significantly across size classes. The general pattern observed was that all arapaima were more likely to be found in deeper, more turbid, and higher conductivity locations, whereas smaller arapaima were more likely to remain near dense beds of floating macrophytes. The probability of arapaima presence differed among fishing community territories, reflecting differences in management schemes.

4. Deeper, macrophyte-rich sections of floodplain lakes appear to provide key habitats for arapaima and deserve consideration for becoming priority targets for conservation of the rich diversity of fish species in these systems.

\section{KEYWORDS}

community-based management, fish conservation, habitat degradation, lake depth, macrophyte beds, várzea, water transparency 


\section{1 | INTRODUCTION}

Tropical river floodplain ecosystems are home to myriads of fish species, but they have been under growing human pressures (Junk, 2002; Tockner \& Stanford, 2002). Large expanses of tropical floodplains have undergone land cover changes, especially deforestation (Renó, Novo, Suemitsu, Rennó, \& Silva, 2011), which are linked to fish population declines (Castello et al., 2018; Arantes et al., 2018). In addition, fishing activities have overfished and depleted several floodplain fish populations (Castello et al., 2013; Coomes, Takasaki, Abizaid, \& Barham, 2010). Many floodplain fishes are vulnerable to fishing pressure, habitat modification and even desiccation when they inhabit floodplain lakes during the dry season (Winemiller \& Jepsen, 1998). Previous studies have linked patterns of fish community structure in floodplain lakes to habitat variables (Arthington, Olden, Balcombe, \& Thoms, 2010; Saint-Paul et al., 2000), but patterns of fish habitat selection by individuals in dry-season floodplain lakes have not been studied. Habitat selection studies can reveal the relative effect of habitat variables on fish distribution patterns, thereby providing useful information for deriving conservation measures to minimize the susceptibility of floodplain fishes to human impacts.

Fish distribution in river floodplains is influenced by seasonal flood pulses (Junk, Bayley, \& Sparks, 1989). Rising waters prompt many fishes to spawn and migrate laterally out of river channels and floodplain lakes onto vegetated floodplain habitats to forage and seek protection from predators (Castello, 2008a; Fernandes, 1997). As waters recede, fish migrate back to river channels and floodplain lakes, and often select larger, deeper floodplain lakes with greater connectivity to river channels (Arantes, Castello, Cetra, \& Schilling, 2013; Granado-Lorencio, Lima, \& Lobón-Cerviá, 2005; Nolan, Fabré, \& Batista, 2009). The structure of fish assemblages in floodplain lakes is affected by water levels, lake depth and wetted perimeter, water temperature and dissolved oxygen, and other factors (Arthington \& Balcombe, 2011; Petry, Bayley, \& Markle, 2003; Saint-Paul et al., 2000). In some cases, the shrinkage of habitat and the consequent deterioration of water quality leads to losses of certain species, as fishes in dry-season floodplain lakes must often tolerate poor water quality characterized by high temperature, low $\mathrm{pH}$ and low levels of dissolved oxygen (Magoulick \& Kobza, 2003). Diminishing habitat availability during the dry season also leads to increases in fish density that intensify predation rates (Matthews \& Marsh-Matthews, 2003 Schlosser, Johnson, Knotek, \& Lapinska, 2000). Fishes also become more vulnerable to fishing gear and local depletion in dry-season floodplain lakes, suffering the bulk of annual fishing mortality (Isaac, Castello, Santos, \& Ruffino, 2016; Welcomme, 1995). The extent and suitability of dry-season habitats are thus key factors regulating fish population dynamics.

Whereas current information on fish distribution patterns in these systems exists at the scale of the floodplain and whole lakes, many of the environmental variables analysed in previous studies vary within dry-season tropical floodplain lakes, which often are heterogeneous in physicochemical parameters (Jardine et al., 2015; Lewis, Hamilton, Lasi, Rodríguez, \& Saunders, 2000). A study in Australia assessed the influence of environmental variables on fish assemblage structure at the floodplain and floodplain lake scales and found that some variables (e.g. lake depth) affected assemblage structure at both scales of analysis (Arthington et al., 2010). If that pattern holds true in other floodplain systems it would mean that environmental variables can predict fish distribution patterns within dry-season floodplain lakes. This would be useful in regions such as the Amazon Basin, where floodplain lakes can be large (i.e. tens of square kilometres) and heterogeneous with respect to physicochemical parameters (Melack \& Forsberg, 2001). In many floodplain lakes of the lower Amazon River, there are efforts to conserve large, overfished and endangered fishes, including Arapaima spp., surubim (Pseudoplatystoma fasciatum) and tambaqui (Colossoma macropomum) (McGrath, Cardoso, Almeida, \& Pezzuti, 2008), but local stakeholders lack guidance on how best to invest their efforts, such as prioritizing protection or restoration of certain components or sections of the lakes (Castello, McGrath, \& Beck, 2011; McGrath et al., 2008).

Fish distribution patterns in dry-season floodplain lakes can also be expected to follow ontogenetic changes, as many fish species demonstrate shifting spatio-temporal distributions across their lifespans (Harvey \& Stewart, 1991; Lecchini, Osenberg, Shima, St Mary, \& Galzin, 2007; Schlosser, 1987). Young fish are often particularly susceptible to predation and chemical and physical stressors (Baumann, Talmage, \& Gobler, 2011; Kurihara, 2008), so risk of predation and foraging profitability are common drivers of habitat selection for them (Mittelbach, 1986; Werner \& Gilliam, 1984). Therefore, in tropical floodplains, where dry-season lakes often possess poor water quality and high predator concentrations, differentiation of habitat selection across life stages may occur as a mechanism to increase survival of young individuals. The larvae and young individuals of many tropical floodplain fishes are known to inhabit stands of riparian macrophyte vegetation (Delariva, Agostinho, Nakatani, \& Baumgartner, 1994; Petry et al., 2003), but within-lake segregation of fish life stages among tropical floodplain habitat types, including riparian macrophyte vegetation, has not been investigated.

Here, as a contribution to understanding this topic, size-structured habitat selection by Arapaima spp. was investigated in dry-season floodplain lakes of the Lower Amazon River. Two research questions were addressed: What factors influence habitat selection by Arapaima spp. within dry-season tropical floodplain lakes, and does dry-season floodplain lake habitat selection by Arapaima spp. vary across lifestages? Arapaima spp. are large, fast-growing fishes that are heavily exploited in dry-season floodplain lakes; they belong to the class of 'sedentary' fishes of the Amazon Basin that spend their entire lifecycles in floodplain habitats (Castello, Stewart, \& Arantes, 2011).

Arapaima are omnivores that consume significant amounts of vegetable matter associated with macrophytes when they are juveniles, and other fishes when they are adults (Carvalho et al., 2018). Juvenile and adult individuals migrate laterally out of floodplain lakes during rising waters and select higher-elevation floodplain habitats when waters are high, migrating back to the lower-lying floodplain lakes when waters recede (Castello, 2008a, 2008b). Arapaima abundances in dry-season floodplain lakes of the central Amazon have been positively correlated with lake depth, area, conductivity, and connectivity to other water bodies (Arantes et al., 2013). Arapaima have historically sustained intense fishing pressure in dry-season floodplain lakes because their need to gulp air reveals their position to harpoon-specialist 
fishers (Castello, 2004). These fishes grow to $80 \mathrm{~cm}$ in total length (TL) in 1 year and a maximum of $3 \mathrm{~m}$, so they are highly sought by fishers (Arantes, Castello, Stewart, Cetra, \& Queiroz, 2010). In the Lower Amazon region, fishing has depleted Arapaima in $75 \%$ of the dry-season floodplain lakes and caused them to become locally extinct in 19\% of 81 fishing communities (Castello, Arantes, McGrath, Stewart, \& Sousa, 2015).

Five species of Arapaima have been described to date, but the taxonomic status, distribution, population status and habitat selection of each species are poorly understood (Castello \& Stewart, 2010; Stewart, 2013a, 2013b). Arapaima gigas was listed in Appendix II of the Convention on International Trade of Endangered Species of Wild Fauna and Flora owing to historical overexploitation. Arapaima gigas is also listed in the IUCN Red List of Threatened Species as 'Data Deficient' (World Conservation Monitoring Centre, 1996). This lack of data also impeded assessment of Arapaima species in Brazil's national list of endangered species. Because of uncertainty about the taxonomic status of Arapaima in the Lower Amazon, it is here referred to by the genus name.

\section{2 | METHODS}

The basis of this study was sampling habitat variables in locations where arapaima were present and absent. To assess the extent to which habitat selection differed across the lifespan, individuals were classified into one of three size classes for comparison. A generalized linear mixed model (GLMM) was used to quantify habitat effects on arapaima presence for each size class.

\section{1 | Study area}

The study area was the Amazon River floodplain near the municipality of Santarém, Pará, Brazil, an area of high concern for arapaima because of marked reductions in their abundance (Castello et al., 2015). The river channels and associated floodplains span more than $50 \mathrm{~km}$ in width and encompass more than 100 fishing communities (Figure 1). Habitat alteration is prevalent in the region, with $56 \%$ of the floodplain deforested between 1970 and 2008 (Renó et al., 2011). Here, 13 floodplain lakes were chosen for sampling on the basis that their morphology (e.g. size, depth) was representative of the lake diversity across the region. Sampled lakes were also chosen based on a previous regional assessment of arapaima populations (Castello et al., 2015); collectively, they included some of the few lakes in the region that still support arapaima densities sufficient to allow a study of habitat selection. The lakes chosen were isolated from other water bodies during the dry season, varied in size from small ( $1 \mathrm{ha}$ ) to large lakes (>10 km in diameter) and were relatively shallow ( $<3 \mathrm{~m}$ ), warm (temperature $>30^{\circ} \mathrm{C}$ ) and turbid (Secchi depth $<1 \mathrm{~m}$ ), although the heterogeneity of the varzea created distinct habitat patches within each lake. The lakes sampled were typically elliptical, with a series of concentric nested habitats within them (Figure 2). In most cases, a large central body of open water was surrounded by floating macrophyte beds 10-100 m wide, which were bordered either by dry, seasonally flooded forests, cattle ranches or dense 'aningal' thickets (Figure 2). Aningal habitats are characterized by stands of Montrichardia arborescens mixed with floodplain trees, so densely concentrated that they prevent entry for habitat sampling.

The sampled lakes were in the territories of six fishing communities with varying management regimes (Table 1), which had to be accounted for because of possible effects on arapaima abundance. All fishing communities were engaged in community-based management (CBM) schemes of fisheries, defined here as management of fisheries undertaken by local communities in collaboration with government organizations; however, there was high variability in the specific ways in which each community performed CBM. Governmental, region-wide rules of arapaima management included a size limit of catch (>1.5 m TL) and a closed season (December to May), which are generally widely violated by fishers (Cavole, Arantes, \& Castello, 2015). Communities involved in CBM typically complement
FIGURE 1 Map of the study area in the Lower Amazon floodplain, depicting 13 sampled lakes and six associated community territories (1: Atuma, 2: Salvaçao; 3: Sao Miguel; 4: Agua Preta; 5: Santa Maria; and 6: Pixuna)

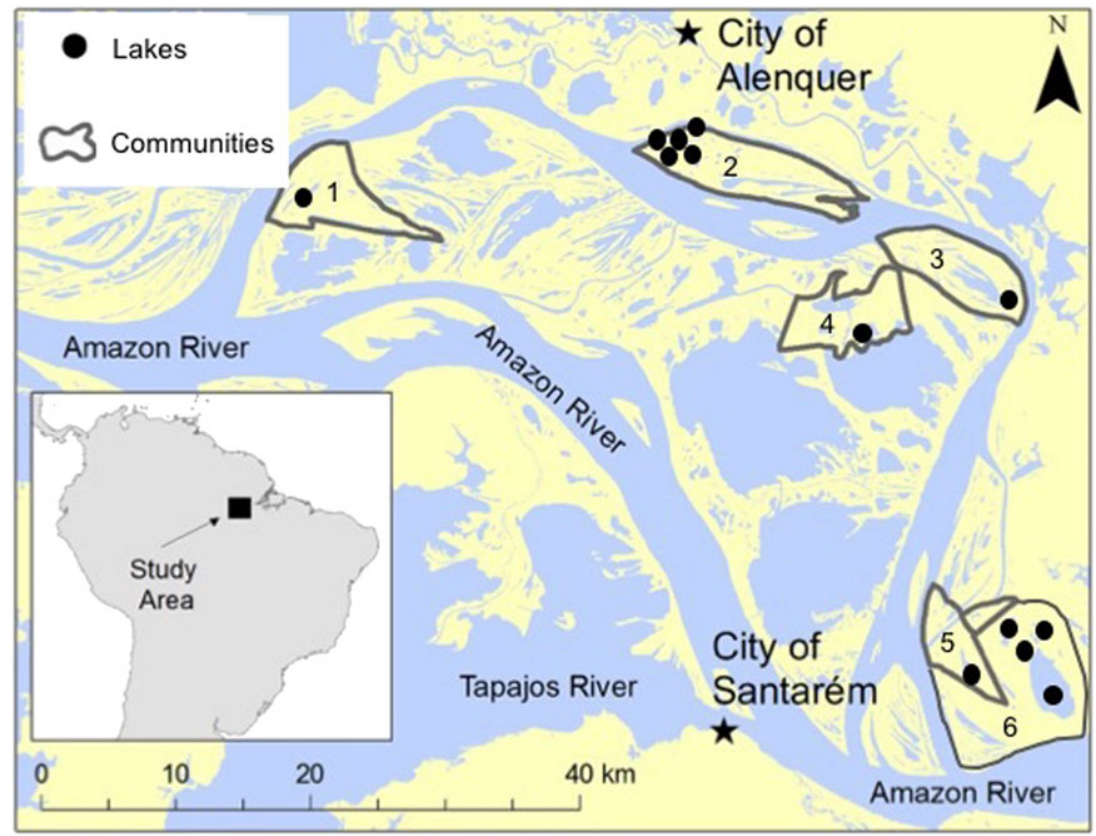




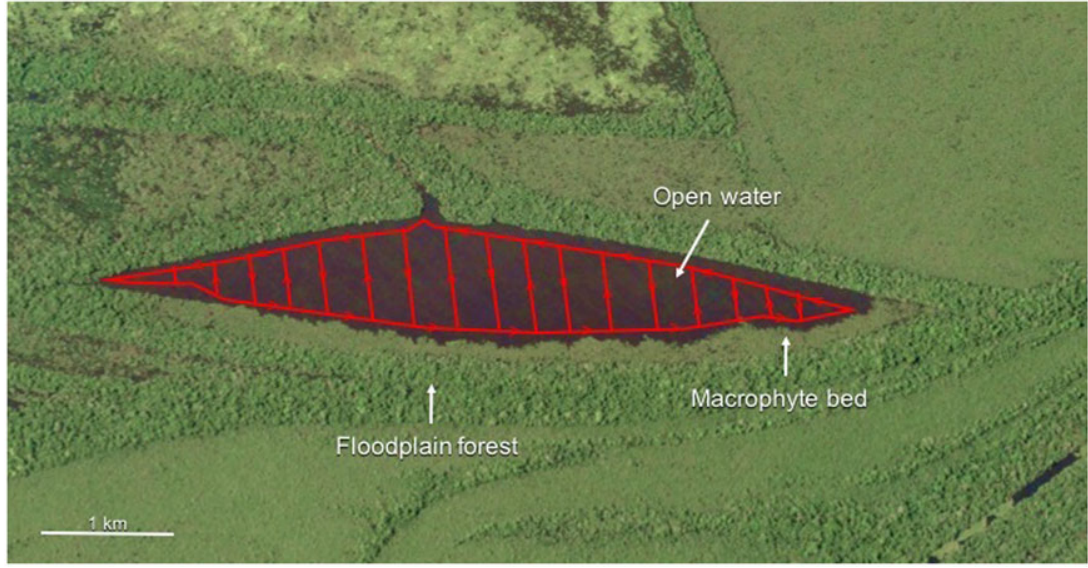

FIGURE 2 Schematic representation of a typical floodplain lake sampled in the Lower Amazon floodplain with respect to arapaima presence/absence and habitat variables. Red lines and arrows denote the typical track navigated by canoe to sample arapaima and habitat variables

TABLE 1 Habitat variable means (plus/minus standard error) for 13 floodplain lakes in the Lower Amazon River (Figure 1)

\begin{tabular}{|c|c|c|c|c|c|c|c|c|c|}
\hline Community & Lake & Depth (m) & $\begin{array}{l}\text { Relative depth } \\
\text { (\%) }\end{array}$ & $\begin{array}{l}\text { Temperature } \\
\left({ }^{\circ} \mathrm{C}\right)\end{array}$ & $\mathrm{pH}$ & $\begin{array}{l}\text { Conductivity } \\
\left(\mu \mathrm{S} \mathrm{cm}^{-1}\right)\end{array}$ & $\begin{array}{l}\text { DO } \\
\left(\mathrm{mg} \mathrm{L}^{-1}\right)\end{array}$ & $\begin{array}{l}\text { Transparency } \\
(\mathrm{cm})\end{array}$ & Distance $(m)$ \\
\hline Tapara-Miri & TM1 & $0.40 \pm 0.07$ & $0.50 \pm 0.09$ & $33.75 \pm 0.34$ & $6.54 \pm 0.03$ & $43.0 \pm 0.5$ & $6.47 \pm 0.07$ & $0.03 \pm 0.00$ & $151.8 \pm 43.1$ \\
\hline Tapara-Miri & TM2 & $1.21 \pm 0.05$ & $0.55 \pm 0.02$ & $31.16 \pm 0.18$ & $6.83 \pm 0.07$ & $44.0 \pm 0.3$ & $5.50 \pm 0.26$ & $0.24 \pm 0.00$ & $55.3 \pm 18.1$ \\
\hline Tapara-Miri & TM3 & $1.50 \pm 0.01$ & $0.84 \pm 0.01$ & $30.53 \pm 0.15$ & $6.10 \pm 0.02$ & $54.0 \pm 0.9$ & $1.54 \pm 0.18$ & $0.78 \pm 0.03$ & $8.3 \pm 2.5$ \\
\hline Tapara-Miri & TM4 & $1.10 \pm 0.07$ & $0.52 \pm 0.03$ & $30.71 \pm 0.08$ & $6.98 \pm 0.04$ & $52.0 \pm 0.5$ & $5.62 \pm 0.23$ & $0.16 \pm 0.01$ & $56.4 \pm 14.2$ \\
\hline Santa Maria & SM1 & $1.28 \pm 0.02$ & $0.71 \pm 0.02$ & $31.27 \pm 0.06$ & $6.52 \pm 0.02$ & $48.0 \pm 0.8$ & $3.08 \pm 0.17$ & $0.43 \pm 0.01$ & $15.7 \pm 2.4$ \\
\hline Illha do Carmo & IDC1 & $1.29 \pm 0.09$ & $0.47 \pm 0.04$ & $31.48 \pm 0.18$ & $6.54 \pm 0.04$ & $60.0 \pm 1.0$ & $2.53 \pm 0.29$ & $0.46 \pm 0.04$ & $15.4 \pm 6.1$ \\
\hline Illha do Carmo & IDC2 & $0.88 \pm 0.05$ & $0.63 \pm 0.04$ & $32.43 \pm 0.28$ & $6.69 \pm 0.05$ & $75.0 \pm 1.3$ & $3.01 \pm 0.36$ & $0.29 \pm 0.01$ & $8.5 \pm 4.4$ \\
\hline Ilha do Carmo & IDC3 & $1.48 \pm 0.05$ & $0.59 \pm 0.02$ & $29.31 \pm 0.05$ & $6.15 \pm 0.01$ & $71.0 \pm 0.8$ & $0.50 \pm 0.04$ & $0.30 \pm 0.01$ & $3.4 \pm 0.6$ \\
\hline Illha do Carmo & IDC4 & $1.04 \pm 0.10$ & $0.45 \pm 0.05$ & $32.30 \pm 0.19$ & $6.80 \pm 0.03$ & $63.0 \pm 0.8$ & $3.34 \pm 0.24$ & $0.31 \pm 0.02$ & $9.5 \pm 3.6$ \\
\hline
\end{tabular}

DO: dissolved oxygen. Distance: distance between an observed fish and the nearest cover (e.g. macrophytes).

government rules by implementing further restrictions of gear and banning commercial fishing in some ('protected') lakes (Castro \& McGrath, 2003). In general, all six communities in this study did not follow government restrictions of size; one community (São Miguel) more or less followed the closed-season restriction, while others did not; two communities (São Miguel and Santa Maria) performed routine lake vigilance efforts and sanctioned rule offenders, suffering low levels of poaching; two communities (IIha do Carmo and Centro do Arapiri) suffered high levels of poaching; and one community (Ilha de São Carmo) performed riparian vegetation restoration, while others did not. Movement patterns of arapaima among lakes when connected by flood waters are unknown.

\section{2 | Sampling}

In order to determine the factors that influence arapaima habitat selection, habitat variables representing the available habitat types in each lake were compared between collective locations where arapaima were observed, and other locations where arapaima were not observed. (From here on, 'sampling locations' refer to the specific points on the surface of the lakes where arapaima presence or absence and related environmental variables were measured.) Lakes were surveyed between 12 November 2014 and 20 December 2014 from a canoe by one of the authors (J.C.R.) and a local fisherman who paddled the perimeter of each lake near the open-water/ macrophyte edge and across transects through open-water areas (Figure 2). To assess habitat availability, eight habitat variables were measured at regular intervals around the perimeter and along the open water transects. These intervals ranged between 75 and $125 \mathrm{~m}$ and were determined for each lake such that habitat sampling could be accomplished in a single day to minimize potential bias stemming from individuals moving around the lakes at night. A paired sampling design was used near edge areas to quantify potential differences in habitat selection between open water and vegetated habitats for a given location. Measurements were taken $10 \mathrm{~m}$ inside the macrophyte bed from the edge and $10 \mathrm{~m}$ in the opposite direction toward the open water.

To assess habitat use, measurements were taken at the exact locations where arapaima were observed surfacing to breathe by a fisher, who was trained in a count method for arapaima that can 
produce accurate population censuses when properly used (Castello, 2004). Observed arapaima were classified by the fisher into one of three size classes: 'small' (<1 m TL), 'medium' (1-1.5 m TL) and 'large' (>1.5 m TL). Based on available information (Arantes et al., 2010), the small size class represents exclusively young fish ( $<2$ years old), the medium size class represents mostly juvenile fish (2-5 years old) and the large size class represents mostly adult fish ( $>5$ years old).

A suite of physicochemical variables was measured, judged to be potentially important to habitat selection by arapaima. At each sampled location, a water quality meter (YSI 556 MPS) was placed just below the surface to measure temperature $\left({ }^{\circ} \mathrm{C}\right)$, dissolved oxygen ( $\mathrm{mg} \mathrm{L}^{-1}$ ), conductivity $\left(\mu \mathrm{S} \mathrm{cm}^{-1}\right.$ ) and $\mathrm{pH}$. A Hawkeye H22PX sonar depth sounder was used to measure depth. For open-water locations, a Secchi disk was used to measure water transparency, and a Nikon Prostaff rangefinder was used to determine distance from the nearest habitat patch providing cover (i.e. macrophyte beds or aningal habitats). Relative depth was estimated at each location to determine whether individuals used the deepest areas available within lakes. Relative depth was calculated by dividing the measured depth at each location by the maximum depth observed within the lake. Because transparency could not be measured under floating macrophyte beds without disturbing sediments, a nearest-neighbour approach (i.e. measurement at the closest location not obscured by macrophytes) was used to avoid problems arising from missing values in the analysis.

\section{3 | Data analysis}

Habitat variables were 'spatialized' before analysis. This approach allowed spatial autocorrelation to be accounted for without sacrificing degrees of freedom in subsequent models owing to the need to include separate spatial variables (Brind'Amour, Boisclair, Legendre, \& Borcard, 2005; Dormann et al., 2007). First, a pairwise Euclidean distance matrix of sampling location coordinates (latitude and longitude) was calculated using the spDistsN1 function in the sp package (Bivand, Pebesma, \& Gomez-Rubio, 2013) in R (R Core Team, 2014). The distance matrix was subjected to a principal coordinates of neighbourhood matrices (PCNM) analysis using the PCNM function from the PCNM package (Legendre, Borcard, Blanchet, \& Dray, 2013) of R. This procedure identified significant gradients in spatial clustering of sampling locations by testing for significance on Moran's I of spatial autocorrelation of eigenvectors $(\alpha=0.05)$. Next, all significant spatial eigenvectors with positive eigenvalues produced by the PCNM analysis were retained and used as potential independent variables in multiple linear regression models to predict each habitat variable. The optimal model for each habitat variable was identified based on the lowest value of Akaike's information criterion using the stepAIC function in the MASS package of R. Finally, subsequent regression models for each variable were created using only the spatial predictors from the optimal model for each habitat variable. Predicted values from these models represent both spatial gradients and habitat characteristics and were retained as factors predicting arapaima presence. Spatialized habitat variables were scaled and centred to mean of zero and variance of one before analysis.
In order to determine the factors influencing arapaima habitat selection across all size classes, a GLMM was developed to predict the probability of arapaima presence based on habitat variables. These variables were pre-screened for multicollinearity using Pearson correlation coefficients in which $|r|>0.7$ indicated an unacceptably high correlation. A GLMM using the glmer function in the Ime4 package of $R$ was used to estimate the effects of habitat variables and fishing community on arapaima presence. Depth, relative depth, temperature, conductivity, $\mathrm{pH}$, dissolved oxygen, transparency and distance from nearest cover were included as fixed effects in the model. To account for the relative influence of CBM on probability of arapaima presence (i.e. population density), the identities of the six communities were included in the model as five fixed dummy variables. This allowed effect sizes to be estimated for all but one community, which was included in the model as a reference with effect size set to zero (Ott \& Longnecker, 2015). A random effect of habitat measurement location nested within community lake identity was included to account for inherent inter-lake variability and nestedness of sample locations in lakes.

Because individual GLMM models cannot estimate the relative importance of individual significant independent variables, an information-theoretic approach was used to estimate the relative importance of each habitat variable in predicting arapaima presence. The dredge function in the MuMin package in $\mathrm{R}$ was used to calculate Akaike weights $w_{i}$ for GLMMs of all possible combinations of independent variables, including an intercept-only model. For each variable, $w_{i}$ was summed for all models containing that variable. Variables with higher summed $w$ values are considered more important (Burnham \& Anderson, 2010).

In order to assess how dry-season habitat selection of arapaima varies across life-stages, linear mixed models were used to evaluate differences in environmental variables across the three size classes of arapaima. Because the goal of this study was to assess differences in habitat selection across size classes, lake identity was specified as a random effect (rather than a fixed effect) in linear mixed models to make inferences that could be generalized across Amazon floodplain lakes. Individual fish located in floating macrophytes were excluded from the linear mixed models assessing differences in distance from nearest cover by size class, as all individuals located in cover areas were recorded as ' 0 ' for the nearest-distance metric. Tukey's honest significant difference was used to create pairwise comparisons between size classes for each habitat variable. All statistical effects were interpreted as significant at $\alpha<0.05$.

\section{3 | RESULTS}

Based on 243 breathing events of arapaima across a range of size classes ( $n=85$ small, 76 medium, 82 large), the models indicated that arapaima presence in dry-season lakes was significantly affected by the following variables: community, depth, relative depth, conductivity and transparency (Figure 3; Tables 1 and 2). The probability of arapaima presence in each lake was significantly different among lakes. GLMM-predicted mean probabilities of arapaima presence ranged from $0.80 \pm 0.02$ for Santa Maria to $0.24 \pm 0.02$ for Tapara-Miri 

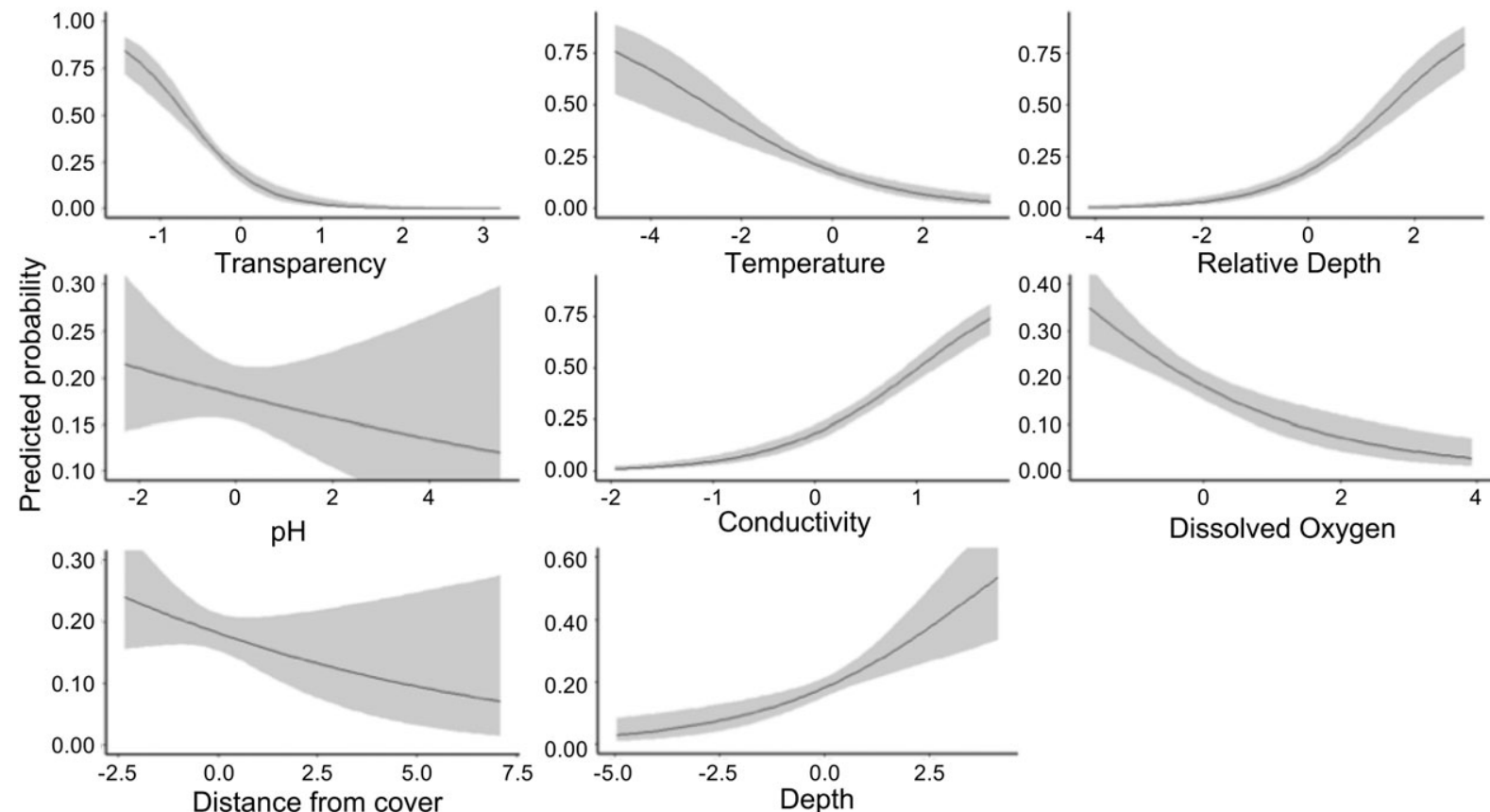

FIGURE 3 Predicted probabilities of arapaima presence based on each of the eight habitat predictors measured. All plots are scaled based on standardized estimates for the spatialized variables and show $95 \%$ confidence intervals in grey

TABLE 2 Parameter estimates ( \pm standard error), $P$-values, cumulative model weights $\left(\Sigma w_{i}\right)$ and relative importance (rank) of habitat variables in generalized linear mixed models predicting arapaima presence in Lower Amazon floodplain lakes

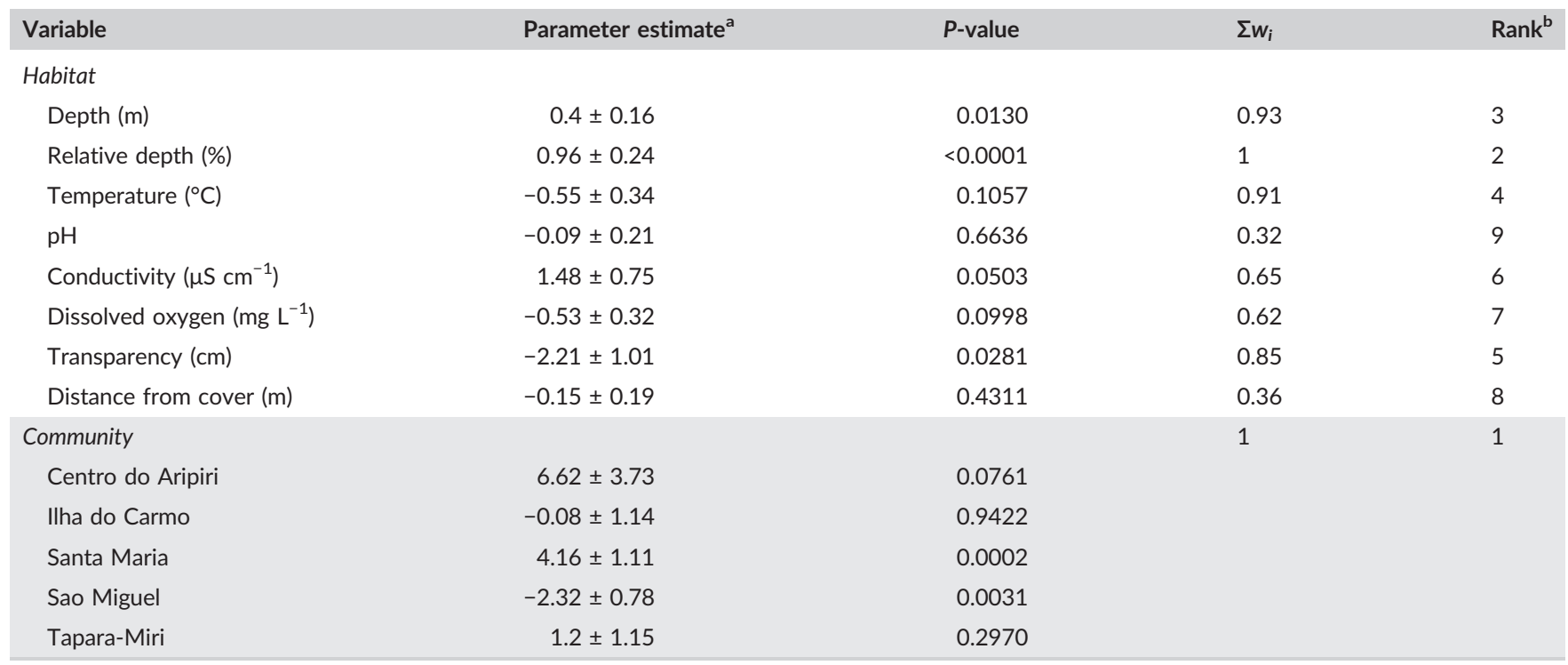

aParameter estimates are given as standardized values, not in their respective measured units. No parameter estimate is available for the Agua Preta community, which is not shown here, because they are set as zero in the model structure. ${ }^{b}$ Ranks range from 1 (most important) to 9 (least important).

and differed among three of the communities surveyed. Santa Maria had the highest community-level mean probability of arapaima presence, followed by São Miguel, while the community-level mean probability of presence of arapaima in all other communities was not significantly different from the mean for all communities (Table 2).

Relative depth and absolute depth had significant positive effects on the probability of arapaima presence $(P<0.001$ and $P=0.013$ respectively), while transparency had a significant negative effect $(P=0.028)$. Conductivity was positively related to arapaima presence at $P=0.05$. Water temperature was consistently included in heavily weighted models, but it was not a statistically significant predictor of arapaima presence. Dissolved oxygen, $\mathrm{pH}$ and distance from cover also did not significantly affect arapaima presence. The most important variable predicting arapaima presence was community $(w=1.0)$, followed by relative depth $(w=0.99)$, absolute depth ( $w=0.93)$, temperature $(w=0.91)$ and transparency $(w=0.85)$, all of which were significant except for temperature (Figure 4). Other variables were less important (Table 2).

Arapaima exhibited distinct patterns of size-structured habitat selection (Figure 5). After accounting for differences among lakes, 


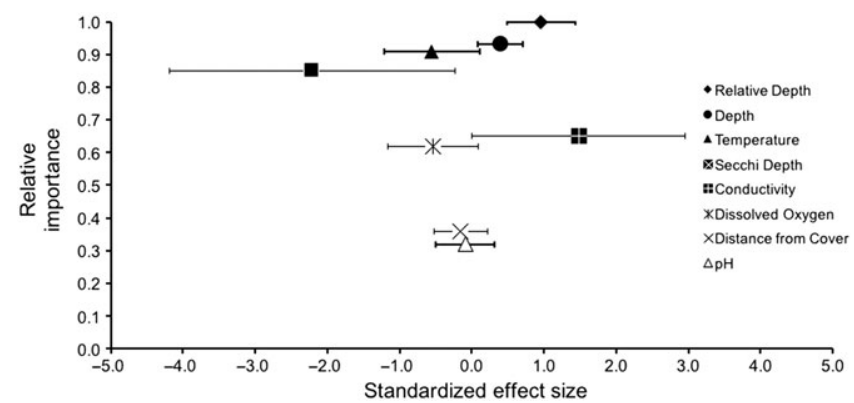

FIGURE 4 Standardized effect size and relative importance to arapaima occurrence for each of the eight habitat variables measured. Error bars for each point show $95 \%$ confidence intervals for estimates

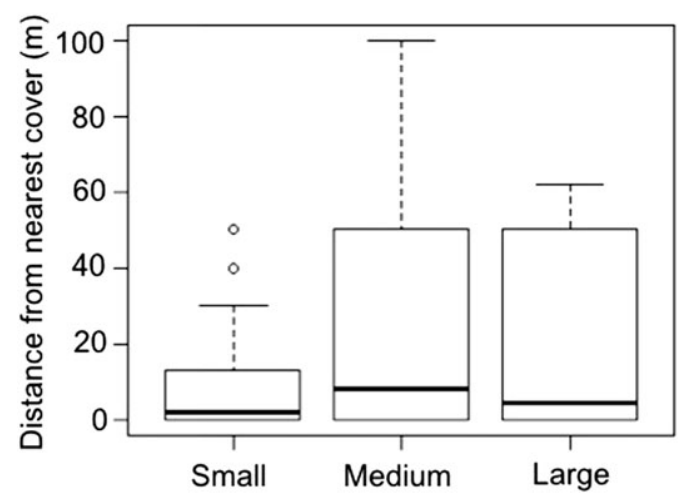

FIGURE 5 Box plots (showing median, first and third quantiles, and extreme values) of distance from nearest cover for small, medium and large arapaima. Small arapaima were observed significantly nearer to cover than medium and large arapaima were, whereas medium and large arapaima were observed at similar distances from cover

distance of fish from nearest cover differed significantly among size classes. For arapaima found in open water, small individuals were located significantly closer to floating macrophyte beds (distance: $12.96 \pm 15.77 \mathrm{~m})$ than medium $(29.07 \pm 22.81 \mathrm{~m})$ and large $(30.33 \pm 21.60 \mathrm{~m})$ individuals (Table 3$)$. Arapaima were found in open-water habitats nearly twice as often as in cover habitats, and habitat type did not differ significantly among size classes (chi-square, $P=0.38$ ). Although depth appeared to differ between small arapaima
$(1.38 \pm 0.06 \mathrm{~m})$ and the two larger size classes (medium: $2.25 \pm$ $0.21 \mathrm{~m}$; large: $1.73 \pm 0.14 \mathrm{~m}$ ), the difference was not significant when the random effect of 'lake' was included. All other pairwise comparisons of habitat variables by size class were non-significant.

\section{4 | DISCUSSION}

Results from this study provide quantitative evidence that an Amazonian fish taxon is heterogeneously distributed within dry-season floodplain lakes. Although macrophyte beds are well known to constitute nursery habitats for a variety of floodplain fishes (Petry et al., 2003), to our knowledge these results are the first to show ontogenetic differentiation of habitat selection for a tropical floodplain fish based on systematic sampling of locations where the individuals were present or absent. As well as showing the effect of CBM on the predicted probability of arapaima presence, the results indicate that arapaima of all sizes select sections of the lakes possessing deeper, more turbid, and higher conductivity waters. Small arapaima individuals select cover, particularly macrophyte edges, and medium and large arapaima individuals select open-water sections, further from macrophyte beds. Some of the variables affecting fish distribution patterns at the floodplain and lake scales (e.g. depth, transparency) also affect arapaima presence within dry-season lakes, thus informing continuing conservation efforts such as CBM that aim to minimize the susceptibility of floodplain fishes to human impacts.

Two of the three communities in which the probability of arapaima presence in the sampling locations in the lakes was higher (Santa Maria and São Miguel) were unique in being the only ones that performed routine vigilance efforts against poaching and sanctioning (i.e. punishment) of rule offenders. Although common-pool resource conservation depends on a multitude of factors (such as defined boundaries), of which vigilance is just one (Cox, Arnold, \& Tomás, 2010; Petersen, Brum, Rossoni, Silveira, \& Castello, 2016), sanctioning rule offenders is widely recognized as a critical determinant that is difficult to execute (McGrath et al., 2008). These results highlight the effect of such efforts on fish distribution patterns in floodplain lakes; however, contrary to expectations, the probability of arapaima presence in lakes of the only community in this study that performed riparian habitat restoration efforts (Ilha do Carmo) was not significantly

TABLE 3 Habitat variable means ( \pm standard error) for three size-classes of arapaima and Tukey honest significant difference (HSD) pairwise comparisons across the three classes: small (S), medium (M), and large (L)

\begin{tabular}{lrrrrrr} 
& & & & \multicolumn{3}{c}{ HSD P-value $^{\mathrm{a}}$} \\
\cline { 5 - 7 } Variable & \multicolumn{1}{c}{ Small } & \multicolumn{1}{c}{ Medium } & Large & S-M & S-L & M-L \\
Depth $(\mathrm{m})$ & $1.38 \pm 0.06$ & $2.25 \pm 0.21$ & $1.73 \pm 0.14$ & 0.3955 & 0.8351 & 0.7085 \\
\hline Relative depth $(\%)$ & $0.66 \pm 0.02$ & $0.65 \pm 0.03$ & $0.65 \pm 0.02$ & 0.3991 & 0.9417 & 0.5610 \\
\hline Temperature $\left({ }^{\circ} \mathrm{C}\right)$ & $30.78 \pm 0.13$ & $30.71 \pm 0.15$ & $30.78 \pm 0.11$ & 0.8346 & 0.3500 & 0.7104 \\
\hline $\mathrm{pH}$ & $6.47 \pm 0.03$ & $6.64 \pm 0.06$ & $6.61 \pm 0.06$ & 0.5620 & 0.1024 & 0.5885 \\
\hline Conductivity $\left(\mu \mathrm{Sm}^{-1}\right)$ & $58.33 \pm 1.31$ & $61.02 \pm 1.09$ & $57.80 \pm 1.14$ & 0.6407 & 0.5643 & 0.9965 \\
\hline Dissolved oxygeb $\left(\mathrm{mg} \mathrm{L}^{-1}\right)$ & $2.30 \pm 0.22$ & $2.83 \pm 0.31$ & $3.18 \pm 0.32$ & 0.2548 & 0.3243 & 0.9734 \\
\hline Transparency $(\mathrm{cm})$ & $0.39 \pm 0.02$ & $0.49 \pm 0.04$ & $0.45 \pm 0.03$ & 0.5060 & 0.2802 & 0.9301 \\
\hline Distance from cover $(\mathrm{m})$ & $12.96 \pm 2.09$ & $29.07 \pm 3.13$ & $30.33 \pm 2.94$ & $0.0332^{*}$ & $0.0058^{*}$ & 0.8597 \\
\hline
\end{tabular}

${ }^{a}$ HSD columns show the $P$-values for pairwise tests between size classes for each variable. Significant $P$-values are indicated with an asterisk. 
different from that in the other communities. This may be because riparian restoration in that community is still incipient or because any gains from it were nullified by poaching.

Results showing that arapaima select deeper, more turbid and higher conductivity waters are consistent with previous studies. Studies in tropical dry-season floodplain lakes identified depth, transparency and conductivity to be important predictors of assemblage structure for fish communities (Pouilly \& Rodríguez, 2004; Rodríguez \& Lewis, 1994, 1997). Arapaima may select the deepest sections within lakes because they can provide safer habitat. Dry-season mortality rates can be high for fish populations in tropical floodplain lakes, owing to increased fish densities, poor water quality and even desiccation (Arthington et al., 2010; Rodríguez \& Lewis, 1994). Water depth can promote survival during periods of low water in several ways. Particularly during droughts, deeper habitat can buffer fishes from increased temperature (Magoulick \& Kobza, 2003; Matthews \& Marsh-Matthews, 2003). High water temperatures may indirectly affect arapaima by forcing their prey to select deeper habitats where water temperatures are lower (Melack \& Forsberg, 2001). The importance of depth for fish habitat selection cannot be overemphasized in these systems. The variability in interannual flood pulse in the Amazon River is large, with the lowest annual water levels varying by up to $7 \mathrm{~m}$ (Ramalho et al., 2009). By selecting deeper lakes during the dry seasons, arapaima may increase their chances of surviving years of extreme drought (e.g. El Niño). Given that mean lake depth in this study was only $1.5 \mathrm{~m}$, compared with the average maximum depth of $4.15 \mathrm{~m}$, fish can be expected not only to select deeper lakes for dry-season survival, as found in the central Amazon (Arantes et al., 2013), but also to select these deep lake sections to avoid desiccation.

Arapaima may select the more turbid sections of lakes to increase their predation success: being ambush predators, arapaima may benefit from habitat that obscures their presence from prey and is generally expected to have higher densities of prey individuals (Turesson \& Brönmark, 2007). Predation of fish has been shown to be a major biotic interaction in tropical floodplains because of the large number of piscivore species in these systems and its capacity to affect fish community structure in dry-season floodplain lakes (Mérona \& Rankin-de-Mérona, 2004; Rodríguez \& Lewis, 1994). Because conductivity is influenced by many factors (e.g. temperature, nutrient concentrations), correlations observed between conductivity and the distribution of floodplain fishes by this and other studies (Arantes et al., 2013; Rodríguez \& Lewis, 1994) deserve further investigation.

Several possibilities relating to ontogenetic shifts in diet and predation risk may explain the tendency of smaller arapaima to remain close to macrophyte beds. In the Amazon these act as nursery grounds for the majority of fish larvae (Petry et al., 2003), where an abundance of refugia and small prey items promotes their survival and growth. Arapaima diets change significantly across their lifespans: whereas juveniles and adults feed almost exclusively on other fishes, the bulk of prey items for arapaima $<1 \mathrm{~m}$ TL comprises insects, molluscs and crustaceans found in macrophyte beds (Queiroz, 2000). Ontogenetic shifts in diet based on gape-size limitations are a well-known aspect of many freshwater fishes (Schael, Rudstam, \& Post, 1991), and arapaima appear to exhibit similar patterns. Smaller arapaima are likely to remain close to macrophyte beds, because these habitats support higher densities of available prey, including crustaceans, insects and small fishes (Junk, 1973). As arapaima grow larger, they can probably venture further out into open-water areas to forage for larger-bodied prey without an increased risk of predation. At the same time, smaller arapaima may remain closer to macrophyte beds to seek cover from a variety of predators. Previous studies have demonstrated size-specific habitat use in freshwater fishes driven by the presence of predators (Holbrook \& Schmitt, 1988; Persson, Andersson, Wahlstrom, \& Eklov, 1996). When predators are present, many fish alter their foraging strategies to exploit less productive areas in exchange for a reduced risk of predation.

The extent to which these findings on habitat selection of arapaima in dry-season floodplain lakes are applicable to other fish taxa in the Amazon and other tropical floodplains needs careful consideration. On the one hand, arapaima have unique bio-ecological features. They are very large-bodied fishes that outgrow all other Amazonian fishes, except one species of goliath catfishes (Brachyplatystoma filamentosum). They are also obligate air-breathers that can tolerate low dissolved oxygen levels that even fishes possessing other morphological and physiological adaptations to anoxia cannot withstand (Graham, 1997). On the other hand, arapaima are omnivores that become piscivores in adult life (Carvalho et al., 2018); piscivory is a very common feeding strategy among Amazonian fishes (Mérona \& Rankin-de-Mérona, 2004). Arapaima also belong to the class of 'sedentary' fishes of the Amazon Basin that spend their entire life cycles in floodplain habitats. Findings herein could thus be generalizable to other sedentary piscivore fishes, such as peacock bass (Cichla ocellatus), arowana (Osteoglossum bicirrhosum) and piranha (Serrasalmus spp.), for which size-structured habitat selection remains unstudied. In that context, the large interannual variability of flood pulses in the Amazon can be expected to have selected for sedentary fishes possessing evolutionary strategies to avoid desiccation by selecting deeper sections of floodplain lakes.

\section{1 | Conservation implications}

These results provide support to existing views that macrophyte beds are priority targets for the conservation of tropical floodplain fishes (Agostinho, Thomaz, Gomes, \& Baltar, 2007), with deep sections of floodplain lakes as additional priority targets for fish conservation efforts in these systems. Macrophyte beds and lake depth are threatened by continuing degradation of Amazonian freshwater habitats associated with cattle ranching and floodplain land-cover changes (Castello \& Macedo, 2016). Cattle in the floodplains frequently graze and trample macrophyte beds, eliminating or dramatically reducing the extent of macrophyte patches (Sheikh, Merry, \& McGrath, 2006). Floodplain deforestation generally takes place in the levees (Renó et al., 2011). Removal of floodplain forests can induce erosion in the levees, thereby promoting sedimentation of floodplain lakes, as observed in the Tonle Sap lake in Cambodia (Campbell, Poole, Giesen, \& Valbo-Jorgensen, 2006). We suggest, therefore, that conserving deep and macrophyte-rich sections of floodplain lakes in the Lower Amazon may require maintaining their original vegetative cover. 
Unfortunately, present legislation offers only scant protection for these floodplains. In Brazil, for example, floodplain protection is mostly based on the Forest Code, which only protects a maximum of $500 \mathrm{~m}$ of floodplain adjacent to river channels even though Amazonian floodplains often extend for tens of kilometres (Castello et al., 2018). Increased levels of protection for the land cover of floodplains may be needed to decrease the vulnerability of floodplain fishes, and this topic warrants further study. Although there was no evidence that ongoing riparian vegetation restoration enhances the probability of arapaima presence in the floodplain lakes of the only community implementing such a conservation strategy, the protection and restoration of native riparian vegetation can be expected generally to increase fish abundance (Arantes et al., 2018) and improve the effectiveness of CBM schemes for fisheries. A challenge in promoting habitat restoration as part of CBM is the long time it takes for new vegetation, especially floodplain forests, to become established. Local fishers may consider that investment of time and effort is too large compared with the time frame over which most of their fisheries management efforts take place. It may thus be necessary to create new mechanisms to complement current legislation in order to foster the protection and restoration of native riparian vegetation. For example, remote-sensing techniques have recently been developed to quantify the change in floodplain land cover, and maps of historical floodplain deforestation in the Lower Amazon region are now available (Renó et al., 2011). These data could be coupled with developing international schemes of payment for ecosystem services to promote protection and restoration of native riparian vegetation in tropical forests. The United Nations programme on Reducing Emissions from Deforestation and Forest Degradation in Developing Countries (known as REDD+) is being implemented in upland regions of many tropical forests mainly to conserve terrestrial ecosystems (Nepstad et al., 2014). The potential benefits of REDD+ for riverine fishes has also been demonstrated (Stickler et al., 2009), and it may be possible to implement this programme in tropical floodplains to help protect, among other things, the lakes that host a significant portion of the world's biodiversity.

\section{ACKNOWLEDGEMENTS}

Ronei, C.C. Arantes and Poly provided valuable assistance in the field. D. Orth gave valuable input to research design, data analysis and the main text. The Virginia Cooperative Fish and Wildlife Research Unit is jointly sponsored by US Geological Survey, Virginia Tech, Virginia Department of Game and Inland Fisheries, and the Wildlife Management Institute. Any use of trade, firm, or product names is for descriptive purposes only and does not imply endorsement by the U.S. Government. The authors declare no conflict of interest.

\section{ORCID}

Leandro Castello (D) https://orcid.org/0000-0002-9968-1584

Brandon K. Peoples (D) https://orcid.org/0000-0002-3954-4908

\section{REFERENCES}

Agostinho, A. A., Thomaz, S. M., Gomes, L. C., \& Baltar, S. L. S. M. A. (2007), Influence of the macrophyte Eichhornia azurea on fish assemblage of the Upper Paraná River floodplain (Brazil). Aquatic Ecology, 41, 611-619.
Arantes, C. C., Castello, L., Cetra, M., \& Schilling, A. (2013). Environmental influences on the distribution of arapaima in Amazon floodplains. Environmental Biology of Fishes, 96, 1257-1267.

Arantes, C. C., Castello, L., Stewart, D. J., Cetra, M., \& Queiroz, H. L. (2010). Population density, growth and reproduction of arapaima in an Amazonian river-floodplain. Ecology of Freshwater Fish, 19, 455-465.

Arantes, C. C., Winemiller, K. O., Petrere, M., Castello, L., Hess, L. L., \& Freitas, C. E. C. (2018). Relationships between forest cover and fish diversity in the Amazon River floodplain. Journal of Applied Ecology, 55, 386-395.

Arthington, A. H., \& Balcombe, S. R. (2011). Extreme flow variability and the 'boom and bust' ecology of fish in arid-zone floodplain rivers: A case history with implications for environmental flows, conservation and management. Ecohydrology, 4, 708-720.

Arthington, A. H., Olden, J. D., Balcombe, S. R., \& Thoms, M. C. (2010). Multi-scale environmental factors explain fish losses and refuge quality in drying waterholes of Cooper Creek, an Australian arid-zone river. Marine and Freshwater Research, 61, 842-856.

Baumann, H., Talmage, S. C., \& Gobler, C. J. (2011). Reduced early life growth and survival in a fish in direct response to increased carbon dioxide. Nature Climate Change, 2, 38-41.

Bivand, R. S., Pebesma, E., \& Gomez-Rubio, V. (2013). Applied spatial data analysis with R. New York, NY: Springer.

Brind'Amour, A., Boisclair, D., Legendre, P., \& Borcard, D. (2005). Multiscale spatial distribution of a littoral fish community in relation to environmental variables. Limnology and Oceanography, 50, 465-479.

Burnham, K. P., \& Anderson, D. R. (2010). Model selection and multimodel inference: A practical information-theoretic approach. New York, NY: Springer.

Campbell, I. C., Poole, C., Giesen, W., \& Valbo-Jorgensen, J. (2006). Species diversity and ecology of Tonle Sap Great Lake, Cambodia. Aquatic Sciences, 68, 355-373.

Carvalho, F., Power, M., Forsberg, B. R., Castello, L., Martins, E. G., \& Freitas, C. E. C. (2018). Trophic ecology of Arapaima sp. in a ria lakeriver-floodplain transition zone of the Amazon. Ecology of Freshwater Fish, 27, 237-246.

Castello, L. (2004). A method to count pirarucu Arapaima gigas: Fishers, assessment, and management. North American Journal of Fisheries Management, 24, 379-389.

Castello, L. (2008a). Lateral migration of Arapaima gigas in floodplains of the Amazon. Ecology of Freshwater Fish, 17, 38-46.

Castello, L. (2008b). Nesting habitat of Arapaima gigas (Schinz) in Amazonian floodplains. Journal of Fish Biology, 72, 1520-1528.

Castello, L., Arantes, C. C., McGrath, D. G., Stewart, D. J., \& Sousa, F. S. D. (2015). Understanding fishing-induced extinctions in the Amazon. Aquatic Conservation: Marine and Freshwater Ecosystems, 25, 587-598.

Castello, L., Hess, L. L., Thapa, R., McGrath, D. G., Arantes, C. C., Renó, V., \& Isaac, V. I. N. (2018). Fish yields vary with land cover on the Amazon river-floodplain. Fish and Fisheries, 19, 431-440.

Castello, L., \& Macedo, N. M. (2016). Large-scale degradation of Amazonian freshwater ecosystems. Global Change Biology, 22, 990-1007.

Castello, L., McGrath, D. G., \& Beck, P. S. (2011). Resource sustainability in small-scale fisheries in the Lower Amazon floodplains. Fisheries Research, 110, 356-364.

Castello, L., McGrath, D. G., Hess, L. L., Coe, M. T., Lefebvre, P. A., Petry, P., ... Arantes, C. C. (2013). The vulnerability of Amazon freshwater ecosystems. Conservation Letters, 6, 217-229.

Castello, L., \& Stewart, D. J. (2010). Assessing CITES non-detriment findings procedures for arapaima in Brazil. Journal of Applied Ichthyology, $26,49-56$.

Castello, L., Stewart, D. J., \& Arantes, C. C. (2011). Modeling population dynamics and conservation of arapaima in the Amazon. Reviews in Fish Biology and Fisheries, 21, 623-640. 
Castro, F., \& McGrath, D. G. (2003). Moving toward sustainability in the local management of floodplain lake fisheries in the Brazilian Amazon. Human Organization, 62, 123-133.

Cavole, L. M., Arantes, C. C., \& Castello, L. (2015). How illegal are tropical small-scale fisheries? An estimate for arapaima in the Amazon. Fisheries Research, 168, 1-5.

Coomes, O. T., Takasaki, Y., Abizaid, C., \& Barham, B. L. (2010). Floodplain fisheries as natural insurance for the rural poor in tropical forest environments: Evidence from Amazonia. Fisheries Management and Ecology, 17, 513-521.

Cox, M., Arnold, G., \& Tomás, S. V. (2010). A review of design principles for community-based natural resource management. Ecology and Society, 15, 38.

Delariva, R. L., Agostinho, A. A., Nakatani, K., \& Baumgartner, G. (1994). Ichthyofauna associated to aquatic macrophytes in the upper Paraná River floodplain. Revista UNIMAR: Ciencias Biologicas e da Saude, 16, 41-60.

Dormann, C. F., McPherson, J. B., Araújo, M., Bivand, R., Bolliger, J., Carl, G. G., ... Kissling, W. D. (2007). Methods to account for spatial autocorrelation in the analysis of species distributional data: A review. Ecography, 30, 609-628.

Fernandes, C. C. (1997). Lateral migration of fishes in Amazon floodplains. Ecology of Freshwater Fish, 6, 36-44.

Graham, J. B. (1997). Air-breathing fishes: Evolution, diversity, and adaptation. New York, NY: Academic Press.

Granado-Lorencio, C., Lima, C. R., \& Lobón-Cerviá, J. (2005). Abundancedistribution relationships in fish assembly of the Amazonas floodplain lakes. Ecography, 28, 515-520.

Harvey, B. C., \& Stewart, A. J. (1991). Fish size and habitat depth relationships in headwater streams. Oecologia, 87, 336-342.

Holbrook, S. J., \& Schmitt, R. J. (1988). Effects of predation risk on foraging behavior: Mechanisms altering patch choice. Journal of Experimental Marine Biology and Ecology, 121, 151-163.

Isaac, V. I. N., Castello, L., Santos, P. S. B., \& Ruffino, M. (2016). Seasonal and interannual dynamics of river-floodplain multispecies fisheries in relation to flood pulses in the Lower Amazon. Fisheries Research, 183 352-359.

Jardine, T. D., Bond, N. R., Burford, M. A., Kennard, M. J., Ward, D. P., Bayliss, P., ... Naiman, R. J. (2015). Does flood rhythm drive ecosystem responses in tropical riverscapes? Ecology, 96, 684-692.

Junk, W. J. (1973). Investigations on the ecology and production biology of the 'floating meadows' (Paspalo echinochloetum) on the Middle Amazon. Part II. The aquatic fauna in the root zone of floating vegetation. Amazoniana, 4, 9-102.

Junk, W. J. (2002). Long-term environmental trends and the future of tropical wetlands. Environmental Conservation, 29, 414-435.

Junk, W. J., Bayley, P. B., \& Sparks, R. E. (1989). The flood pulse concept in river-floodplain systems. In D. P. Dodge (Ed.), Proceedings of the International Large River Symposium ( ed., Vol. 106). Canadian Special Publication of Fisheries and Aquatic Sciences. (pp. 110-127). Ottawa, Canada: Department of Fisheries and Oceans.

Kurihara, $\mathrm{H}$. (2008). Effects of $\mathrm{CO}_{2}$-driven ocean acidification on the early developmental stages of invertebrates. Marine Ecology Progress Series, 373, 275-284.

Lecchini, D., Osenberg, C. W., Shima, J. S., St Mary, C. M., \& Galzin, R. (2007). Ontogenetic changes in habitat selection during settlement in a coral reef fish: Ecological determinants and sensory mechanisms. Coral Reefs, 26, 423-432.

Legendre, P., Borcard, D., Blanchet, F. G., \& Dray, S. (2013). PCNM: MEM spatial eigenfunction and principal coordinate analyses. R package version 2.1-2/r109. http://R-Forge.R-project.org/projects/sedar/.[30 September 2017].

Lewis, W. M., Hamilton, S. K., Lasi, M. A., Rodríguez, M., \& Saunders, J. F. (2000). Ecological determinism on the Orinoco floodplain. Bioscience, 50, 681-692.
Magoulick, D. D., \& Kobza, R. M. (2003). The role of refugia for fishes during drought: A review and synthesis. Freshwater Biology, 48, 1186-1198.

Matthews, W. J., \& Marsh-Matthews, E. (2003). Effects of drought on fish across axes of space, time and ecological complexity. Freshwater Biology, 48, 1232-1253.

McGrath, D. G., Cardoso, A., Almeida, O. T., \& Pezzuti, J. (2008). Constructing a policy and institutional framework for an ecosystem-based approach to managing the Lower Amazon floodplain. Environment, Development and Sustainability, 10, 677-695.

Melack, J. M., \& Forsberg, B. R. (2001). Biogeochemistry of Amazon floodplain lakes and associated wetlands. In M. E. McClain, R. L. Victoria, \& J. E. Richey (Eds.), The biogeochemistry of the Amazon Basin (pp. 235-274). Oxford, UK: Oxford University Press.

Mérona, B. D., \& Rankin-de-Mérona, J. (2004). Food resource partitioning in a fish community of the central Amazon floodplain. Neotropical Ichthyology, 2, 75-84.

Mittelbach, G. (1986). Predator-mediated habitat use: Some consequences for species interactions. Environmental Biology of Fishes, 16, 159-169.

Nepstad, D., McGrath, D., Stickler, C., Alencar, A., Azevedo, A., Swette, B., ... Armijo, E. (2014). Slowing Amazon deforestation through public policy and interventions in beef and soy supply chains. Science, 344, 1118-1123.

Nolan, K. S., Fabré, N. N., \& Batista, V. S. (2009). Landscape variables affecting fishery yield in lake systems of the central Amazon region, Brazil. Journal of Applied Ichthyology, 25, 294-298.

Ott, R. L., \& Longnecker, L. T. (2015). An introduction to statistical methods and data analysis. New York, NY: Nelson Education.

Persson, L., Andersson, J., Wahlstrom, E., \& Eklov, P. (1996). Size-specific interactions in lake systems: Predator gape limitation and prey growth rate and mortality. Ecology, 77, 900-910.

Petersen, T. A., Brum, S. M., Rossoni, F., Silveira, G. F. V., \& Castello, L. (2016). Recovery of Arapaima sp. populations by community-based management in floodplains of the Purus River, Amazon. Journal of Fish Biology, 89, 241-248.

Petry, P., Bayley, P. B., \& Markle, D. F. (2003). Relationships between fish assemblages, macrophytes and environmental gradients in the Amazon River floodplain. Journal of Fish Biology, 63, 547-579.

Pouilly, M., \& Rodríguez, M. (2004). Determinism of fish assemblage structure in neotropical floodplain lakes: Influence of internal and landscape lake conditions. In R. L. Welcomme, \& T. Petr (Eds.), Proceedings of the second international symposium on the management of large rivers for fisheries: Sustaining livelihoods and biodiversity in the new millennium (ed., Vol. 2) (pp. 243-265). Rome, Italy: Food and Agriculture Organization of the United Nations.

Queiroz, H. L. (2000). Natural history and conservation of pirarucu, Arapaima gigas, at the Amazonian várzea: Red giants in muddy waters (PhD thesis). University of St. Andrews, Scotland, UK.

R Core Team. (2014). R: A language and environment for statistical computing. R Foundation for Statistical Computing: Vienna, Austria. https:// www.r-project.org [30 September 2017].

Ramalho, E. E., Macedo, J., Vieira, T. M., Valsecchi, J., Calvimontes, J., Marmontel, M., \& Queiroz, H. L. (2009). Ciclo hidrológico nos ambientes de várzea da Reserva de Desenvolvimento Sustentável Mamirauá-Médio Solimões, período de 1990 a 2008. Uakari, 5, 58-65.

Renó, V. F., Novo, E. M. L. M., Suemitsu, C., Rennó, C. D., \& Silva, T. S. F. (2011). Assessment of deforestation in the Lower Amazon floodplain using historical Landsat MSS/TM imagery. Remote Sensing of Environment, 115, 3446-3456.

Rodríguez, M. A., \& Lewis, W. M. (1994). Regulation and stability in fish assemblages of neotropical floodplain lakes. Oecologia, 99, 166-180.

Rodríguez, M. A., \& Lewis, W. M. (1997). Structure of fish assemblages along environmental gradients in floodplain lakes of the Orinoco River. Ecological Monographs, 67, 109-128. 
Saint-Paul, U., Zuanon, J., Villacorta-Correa, M. A., Garcia, M., Fabre, N. N., Berger, U., \& Junk, W. J. (2000). Fish communities in central Amazonian white- and blackwater floodplains. Environmental Biology of Fishes, 57, 235-250.

Schael, D. M., Rudstam, L. G., \& Post, J. R. (1991). Gape limitation and prey selection in larval yellow perch (Perca flavescens), freshwater drum (Aplodinotus grunniens), and black crappie (Pomoxis nigromaculatus). Canadian Journal of Fisheries and Aquatic Sciences, 48, 1919-1925.

Schlosser, I. J. (1987). The role of predation in age- and size-related habitat use by stream fishes. Ecology, 68, 651-659.

Schlosser, I. J., Johnson, J. D., Knotek, W. L., \& Lapinska, M. (2000). Climate variability and size-structured interactions among juvenile fish along a lake-stream gradient. Ecology, 81, 1046-1057.

Sheikh, P. A., Merry, F. D., \& McGrath, D. G. (2006). Water buffalo and cattle ranching in the lower Amazon Basin: Comparisons and conflicts. Agricultural Systems, 87, 313-330.

Stewart, D. J. (2013a). A new species of Arapaima (Osteoglossomorpha: Osteoglossidae) from the Solimões River, Amazonas State, Brazil. Copeia, 2013, 470-476.

Stewart, D. J. (2013b). Re-description of Arapaima agassizii (Valenciennes), a rare fish from Brazil (Osteoglossomorpha: Osteoglossidae). Copeia, 2013, 38-51.

Stickler, C. M., Nepstad, D. C., Coe, M. T., McGrath, D. G., Rodrigues, H. O., Walker, W. S., ... Davidson, E. A. (2009). The potential ecological costs and cobenefits of REDD: A critical review and case study from the Amazon region. Global Change Biology, 15, 2803-2824.
Tockner, K., \& Stanford, J. A. (2002). Riverine flood plains: Present state and future trends. Environmental Conservation, 29, 308-330.

Turesson, H., \& Brönmark, C. (2007). Predator-prey encounter rates in freshwater piscivores: Effects of prey density and water transparency. Oecologia, 153, 281-190.

Welcomme, R. L. (1995). Relationships between fisheries and the integrity of river systems. Regulated Rivers: Research \& Management, 11, 121-136.

Werner, E. E., \& Gilliam, J. F. (1984). The ontogenetic niche and species interactions in size-structured populations. Annual Review of Ecology and Systematics, 15, 393-425.

Winemiller, K. O., \& Jepsen, D. B. (1998). Effects of seasonality and fish movement on tropical river food webs. Journal of Fish Biology, 53, 267-296.

World Conservation Monitoring Centre. (1996). Arapaima gigas. The IUCN Red List of Threatened Species 1996: e.T1991A9110195. https://doi. org/10.2305/IUCN.UK.1996.RLTS.T1991A9110195.en. [26 May 2018]

How to cite this article: Richard JC, Castello L, Gurdak DJ, Peoples BK, Angermeier PL. Size-structured habitat selection by arapaima in floodplain lakes of the Lower Amazon. Aquatic Conserv: Mar Freshw Ecosyst. 2018;28:1403-1413. https:// doi.org/10.1002/aqc.2969 